\title{
Adverse events associated with nicotine replacement therapy (NRT) for smoking cessation. A systematic review and meta-analysis of one hundred and twenty studies involving 177,390 individuals
}

Edward J Mills ${ }^{{ }^{*}}$, Ping Wu ${ }^{2}$, lan Lockhart ${ }^{3}$, Kumanan Wilson ${ }^{4}$, Jon O Ebbert ${ }^{5}$

\begin{abstract}
Background: Nicotine replacement therapy (NRT) is the most common form of smoking cessation pharmacotherapy and has proven efficacy for the treatment of tobacco dependence. Although expectations of mild adverse effects have been observed to be independent predictors of reduced motivation to use NRT, adverse effects associated with NRT have not been precisely quantified.
\end{abstract}

Objective: A systematic review and meta-analysis aimed to identify all randomized clinical trials (RCTs) of NRT versus inert controls and all observational studies to determine the magnitude of reported adverse effects with NRT.

Methods: Searches of 10 electronic databases from inception to November 2009 were conducted. Study selection and data extraction were carried out independently in duplicate. RCTs were pooled using a random effects method with Odds Ratio [OR] as the effect measure, while proportions were pooled from observational studies. A meta-regression analysis was applied to examine whether the nicotine patch is associated with different adverse effects from those common to orally administered NRT.

Results: Ninety-two RCTs involving 32,185 participants and 28 observational studies involving 145, 205 participants were identified. Pooled RCT evidence of varying NRT formulations found an increased risk of heart palpitations and chest pains (OR 2.06, 95\% Confidence Interval [Cl] 1.51-2.82, P<0.001); nausea and vomiting (OR 1.67, 95\% Cl 1.37-2.04, $\mathrm{P}<0.001$ ); gastrointestinal complaints (OR 1.54, 95\% Cl, 1.25-1.89, $\mathrm{P}<0.001$ ); and insomnia (OR 1.42, 95\% $\mathrm{Cl}, 1.21-1.66, \mathrm{P}<0.001)$. Pooled evidence specific to the NRT patch found an increase in skin irritations (OR 2.80, $95 \% \mathrm{CO}, 2.28-3.24, \mathrm{P}<0.001)$. Orally administered NRT was associated with mouth and throat soreness (OR 1.87, $95 \% \mathrm{Cl}, 1.36-2.57, \mathrm{P}<0.001)$; mouth ulcers (OR 1.49, 95\% Cl, 1.05-2.20, $\mathrm{P}<0.001)$; hiccoughs (OR 7.68, 95\% Cl, $4.59-12.85, \mathrm{P}<0.001)$ and coughing (OR 2.89, 95\% Cl, 1.92-4.33, $\mathrm{P}<0.001)$. There was no statistically significant increase in anxiety or depressive symptoms associated with NRT use. Non-comparative observational studies demonstrated the prevalence of these events in a broad population.

Conclusion: The use of NRT is associated with a variety of side effects. In addition to counseling and medical monitoring, clinicians should inform patients of potential side effects which are associated with the use of NRT for the treatment of tobacco dependence.

\footnotetext{
* Correspondence: emills@sfu.ca

${ }^{1}$ Faculty of Health Sciences, University of Ottawa, Ottawa, Canada
} 


\section{Introduction}

Smoking is the leading cause of preventable mortality world wide[1]. One in every 2 long-term smokers will die a smoking related death[2]. Stopping smoking has a considerable impact on improving life expectancy, reducing morbidity and reducing health care costs associated with treating smoking related conditions[3].

Several pharmacological interventions to assist in smoking cessation are available[4]. The most commonly used formulation is nicotine replacement therapy (NRT), frequently available over the counter (OTC). NRT is currently recommended as a safe intervention to general populations and higher-risk groups, including pregnant and breastfeeding women, adolescents, and smokers with cardiovascular disease[5]. NRT improves cessation rates at one year by approximately $70 \%$ (odds ratio [OR] 1.70, 95\% Confidence Interval [CI] 1.55-1.88) $[4,6]$.

Available research suggests that smokers are less motivated to use NRT if they expect that it will cause mild adverse effects[7]. Published systematic reviews of NRT have not explicitly synthesized the incidence of side effects of NRT products. An understanding of the nature and likelihood of the most common side effects may help clinicians communicate to patients the benefits and risks associated with their use of NRT. This information may also improve selection of specific delivery mechanisms based upon patient history, which may improve treatment adherence. While RCTs provide strong information on causation of adverse events, observational studies may report on associations or hypotheses about more rare events. To determine the frequency and incidence of adverse events associated with NRT, we conducted a systematic review and metaanalysis of RCT's and observational studies of NRT in any delivery formulation. Our clinical question is, in patients receiving NRT for smoking cessation, compared to inert controls, what is the incidence of adverse events and what are those adverse events?

\section{Methods}

\section{Eligibility criteria}

We included RCTs of any duration beyond 4 weeks. RCTs had to compare NRT with an inert control (eg. placebo or standard of care). We chose 4 weeks to include the timeframe of maximum nicotine withdrawal symptoms so that adverse events may be differentiated from withdrawal symptoms[8]. We additionally sought out observational studies to examine the proportion of events occurring[9]. We evaluated adverse effects reported at any point in the duration of the studies. We included any form of NRT delivery (i.e. lozenge, skin patch, gum, nasal spray, inhaler, and tablet). We did not examine efficacy in this analysis. We excluded post-hoc analyses, maintenance therapy, or relapse prevention studies.

\section{Search strategy}

In consultation with a medical librarian, we established a search strategy. We searched independently, in duplicate, the following 10 databases (from inception to November 20, 2009): MEDLINE, EMBASE, Cochrane CENTRAL, AMED, CINAHL, TOXNET, Development and Reproductive Toxicology, Hazardous Substances Databank, Psych-info and Web of Science. Given that observational studies are poorly indexed in many databases, we also searched databases that include the full text of journals (ScienceDirect, and Ingenta, including articles in full text from approximately 1700 journals since 1993)[10]. In addition, we searched the bibliographies of published systematic reviews and health technology assessments[4-6,11-16]. Searches were not limited by language, sex or age.

\section{Study selection}

Two investigators (EM, PW) working independently, in duplicate, scanned all abstracts and obtained the full text reports of records indicating that the study was either an RCT or observational study evaluating NRT on the outcomes of interest. After obtaining full reports of the candidate studies (either in full peer-reviewed publication or press article) the same reviewers independently assessed eligibility via full text review.

\section{Data collection}

Two reviewers (EM, PW) conducted data extraction independently using a standardized pre-piloted form. Reviewers collected information about the NRT intervention tested, the population studied (age, sex, underlying conditions), treatment dosages and dosing schedules, the specific measurement of abstinence (prolonged or point-prevalence), and the methods of biochemical confirmation. The reviewers extracted data on adverse events characterized by the study authors as physical or mental adverse events. Recognizing that adverse events may include both physical and mental effects concomitantly, we defined physical adverse events as effects confined to physical parts of the body and mental adverse events as symptoms accompanied by psychological conditions. We characterized serious adverse events as unexpected life-threatening events occurring during the trial period. A priori, we examined the follow life-threatening adverse events: all-cause mortality, myocardial infarction, all-cause strokes, incidence of all-cancers, all-hospitalizations, suicidal ideation, depression, and incidence of diabetes. Study quality evaluation included general methodological reporting features including allocation concealment, sequence generation, blinding 
status, intention-to-treat, and appropriate descriptions of loss to follow-up. In rating quality, failure to report a quality component of study design (e.g. blinding) was treated the same as not employing it. We entered the data into an electronic database such that duplicate entries existed for each study. When the two entries did not match, we resolved differences through discussion and consensus. In the absence of an inert control group, we considered randomized NRT dosing studies to be observational studies and collected data on proportion of combined events. For cohort studies, we additionally calculated events as proportions of events.

\section{Data analysis}

In order to assess inter-rater reliability on inclusion of articles, we calculated the Phi statistic $(\varphi)$, which provides a measure of inter-observer agreement independent of chance[17]. We calculated the Odds Ratios [OR] and appropriate $95 \%$ Confidence Intervals [CIs] of outcomes according to the number of events reported in the original studies or sub-studies. Given that zero events in one treatment arm prevents a useful ratio from being developed, in circumstances of zero outcome events in one arm of a trial, we added 0.5 to each arm, as suggested by Sheehe[18]. We first pooled studies of all NRT interventions versus all controls using the DerSimonian-Laird random effects method[19], which recognizes and anchors studies as a sample of all potential studies, and incorporates an additional betweenstudy component to the estimate of variability[20]. We calculated the $\mathrm{I}^{2}$ statistic for each analysis as a measure of the proportion of the overall variation that is attributable to between-study heterogeneity[21]. Given that we are examining adverse events, interpreting heterogeneity estimates can be challenging as even pooled analysis with large heterogeneity may provide important insights into the likelihood of events[9]. We considered an $\mathrm{I}^{2}$ above $50 \%$ as moderate to large heterogeneity and examined explanations of heterogeneity by applying a random effects meta-regression with the following co-variates: oropharyngeal formulation vs. skin patch; duration of study (in months); reporting of allocation concealment, and reporting of blinding status. We then calculated the residual heterogeneity and present it as the residual $\mathrm{I}^{2}$. Forest plots are displayed for each primary analysis, showing pooled study effect measures with 95\% CIs, and the overall DerSimonian-Laird pooled estimate. For studies considered as observational studies, we calculated pooled weighted proportions by first stabilizing the variances of the raw proportions $(r / n)$ using a Freeman-Tukey type arcsine square root transformation and applying a random effects model. While several methods of pooling proportions exist, the FreemanTukey method works well with both fixed and random effects meta-analysis and truncates at zero[22]. This is a variance-stabilizing transformation that removes the dependence of the variance on the mean of the transformed proportion (ie. it corrects for overdispersion). Assessing heterogeneity in pooled proportions may be misleading $[23,24]$, therefore we report the $\mathrm{I}^{2}$ value, as this measure is less affected by the number of studies as the more commonly used $\mathrm{I}^{2}$. The square root of this number (i.e. tau $[\boldsymbol{\tau}]$ ) is the estimated standard deviation of underlying effects across studies[25]. As with the RCT analysis, we applied a random-effects meta-analysis. Analyses were conducted using StatsDirect (version 2.5.2) and Comprehensive Meta-analysis (version 2).

\section{Results}

Study inclusion and methods reporting (Figure 1)

One hundred and twenty studies met our inclusion criteria $(\varphi=0.91)$ [26-117,110,118-141]. Figure 1 displays the search break-down. Additional file 1 and Table 1 provide study characteristics. Ninety-two studies[26-117] were RCTs involving 32,185 participants and 28[56,75, 93,110,118-141] were considered as observational studies involving 145, 205 participants.

Of RCTs, eighty-three [26-34,37-64,66,105-109,65, 67-85,87-90,92-97,99-102,112,114-117,142](83/92) used a placebo control. Forty-two[39-41,43,45,47-49,51-55, 60,61,64,66,68-72,74-77,81,83,87,89,90,92,93,98,99,102, $103,105-107,112,115]$ evaluated the nicotine patch; 26 $[26-38,42,56,58,79,88,95,100,101,108,109,113,116,142]$ the nicotine gum; $6[44,50,57,65,73,111]$ the nicotine nasal spray; $6[46,62,63,67,78,96]$ the nicotine inhaler; 4 $[80,84,97,114]$ the nicotine tablet; $1[85]$ the nicotine lozenge; and, the remainder $(n=35)$ evaluated NRT combination therapies. Duration of treatment ranged from 1 to 24 months, with varying levels of dosages for each form of NRT.

Seventy-four RCTs[26-31,33-41,43-65,67-70,72-80, 82-88,92,93,95,96,99-101,103,106-109,114-117] were conducted in healthy adult populations. An additional 6 $[36,66,89,97,105,113]$ were conducted among populations with medical and psychiatric co-morbidities (.eg. smokingrelated diseases, chronic diseases, alcoholism, depression), $4[81,98,104,142]$ among pregnant women, 3[42,71,91] among hospitalized patients, $3[90,94,111]$ among adolescents, 1 [102] among postmenopausal women, and 1[112] among surgical patients. Fifty-nine [27-30,33,36-38,41,42, 45,48-56,58,59,61-63,66,67,71,73,74,76,77,79,81,83,86,8992,94,97-102,104-108,111,113-117,142]RCTs included co-interventions, of which $20[27,36,49-52,54,61,71,79,81$, $91,98,100-102,111,114,116,117]$ provided general counseling (eg. group counseling or individual counseling), 19 $[28,41,53,56,61,63,67,76,85,89,90,92,94,99,104-107,113]$ provided behavioural or psychological treatment, 12 $[29,30,33,37,42,45,55,62,66,74,86,97]$ provided varying 
578 abstracts screened for inclusion after searching with "nicotine" AND "smoking" AND "gum" OR "Patch" OR "spray" OR "inhalers" OR "Tablet" OR "lozenge" AND "clinical trial"

12 full text paper publications retrieved for potential inclusion

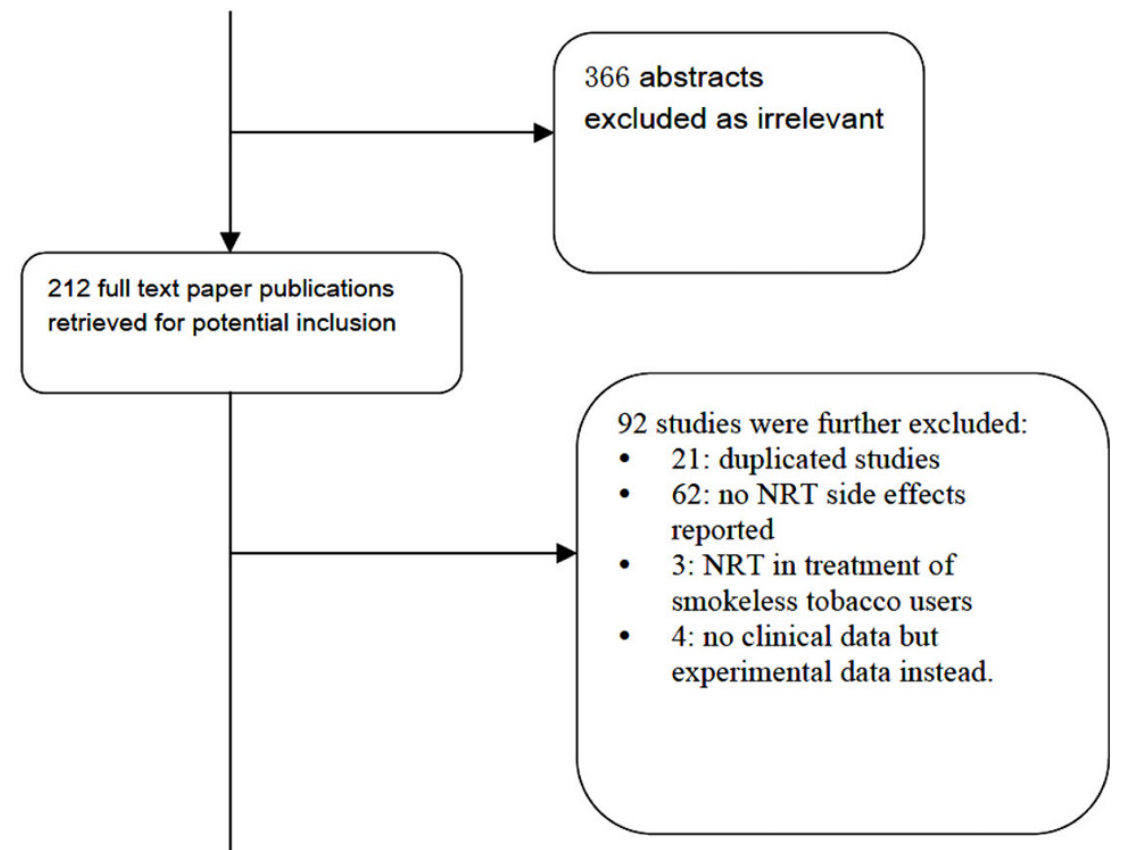

120 studies included: 92 RCTs

28 studies considered observational

Figure 1 low-diagram of included studies.

forms of advice or support, 3[38,108,142] provided educational sessions, $4[58,59,73,77]$ provided an additional NRT and/or placebo, and 1[115] provided rimonabant, an endocannabinoid antagonist used as an appetite suppressant.

Seventeen observational studies[75,93,110,119-124, 126-129,131-133,141] used the nicotine patch; 2 [125, 135] used a nasal spray, 1[129] used the nicotine gum; and 8 used a combination of NRTs. Duration of treatment ranged from 4 to 26 weeks, with varying levels of dosages for each form of NRT. Sixteen $[56,75,93,110,118,122,123,125-127,129,130,132-134,137]$ of the observational studies were conducted among healthy adult populations, $7[120,121,131,135,138-140]$ among mixed healthy and unhealthy adult populations, $2[136,141]$ among adult populations with medical comorbidities, 2[124,128] among adolescent populations, 


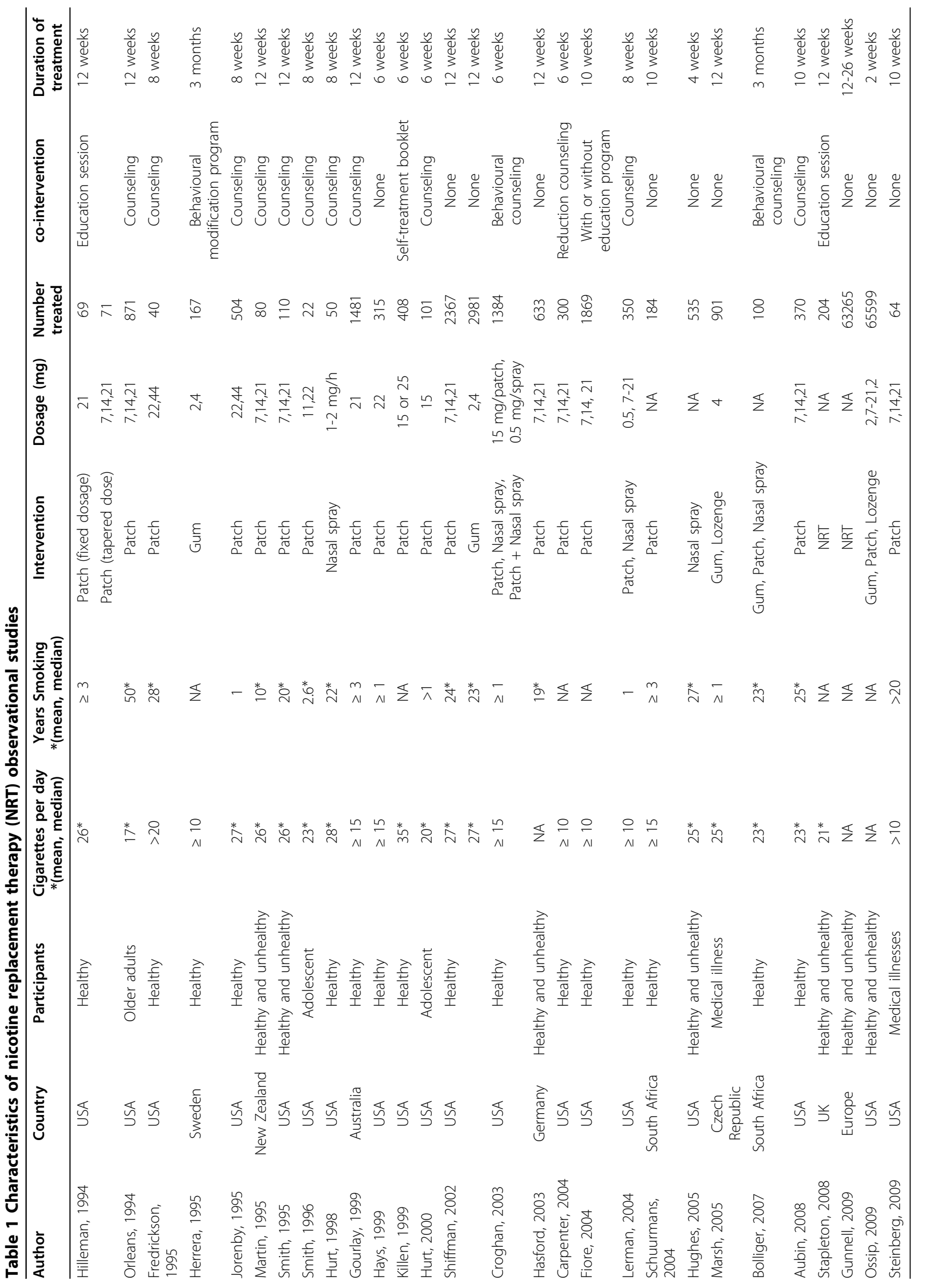


and 1[119] among an older adult population. The majority of observational studies[110,119-126,128, $133,134,56,118,127,130,132,137,138](19 / 28)$ included co-interventions, with $12[110,119-126,128,133,134]$ providing general counseling; $3[56,130,137]$ providing counseling specific to behaviour or behaviour modification; $3[118,132,138]$ providing educational sessions; and 1 [127]providing a self-help booklet.

Studies reported methodological issues variably. Thirtyeight RCTs[28,29,31,37,41,44,46,59,61-63,65,70-75,77,78, $81,82,84,85,90,93,97-99,101,102,104,105,112,115-117,142]$ reported sequence generation of randomization; 17 $[28,29,31,37,59,63,67,69,71,73-75,81,93,98,99,115]$ reported allocation concealment; and, 81[26-34,37-64,66,105107,109,65,67-80,82-85,87-90,92-97,99-102,112,114-117, 142] reported on patient blinding in the study. To confirm smoking abstinence, eighty four[26-28,30-46,48-64, 66,105,107-109,65,67,69-80,83-98,100-104,111,112,114$117,142]$ studies used exhaled carbon monoxide (CO); 16 $[34,35,37,41,45,55,57,62,63,79,81,90,94,107,111,142]$ used salivary cotinine; $5[29,36,47,60,101]$ used serum cotinine; and $2[99,114]$ used urinary cotinine. No studies required participants to pay for the NRT. In 80 studies, [26-29,3141,43-54,56-64,66,105-109,113,65,67,68,70-72,74-77,79, 80,83-87,89,90,92-94,97-104,111,112,114-117,142] participants were planning on quitting. All observational studies are considered as non-comparative single-arm studies reporting prevalence of the adverse events in the community.

\section{Adverse events}

\section{RCTs (See Figure 2)}

We evaluated all forms of NRT for adverse events. Additional file 1 displays the study characteristics and table 2 displays the RCT findings.

\section{Cardiovascular and respiratory}

A pooled analysis of 12 RCTs found a statistically significant increased risk for heart palpitations and chest pains associated with NRT (OR 2.06, 95\% CI, 1.51-2.82, p < $\left.0.001 ; \mathrm{I}^{2}=0 \%\right)$. Applying meta-regression, both the nicotine patch and orally administered NRT were associated with an increased risk (OR 1.11, 95\% CI, 0.53-2.33,

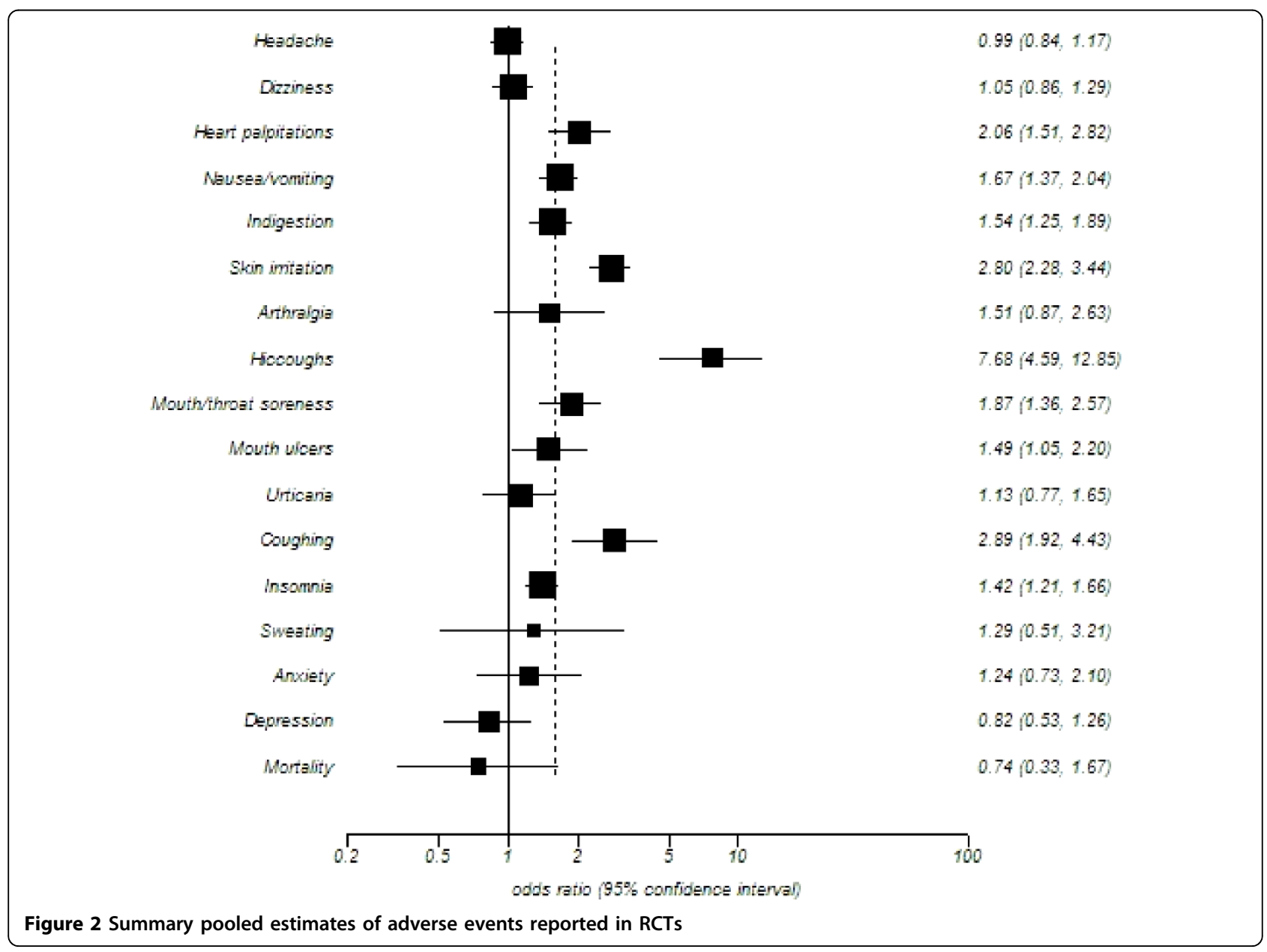




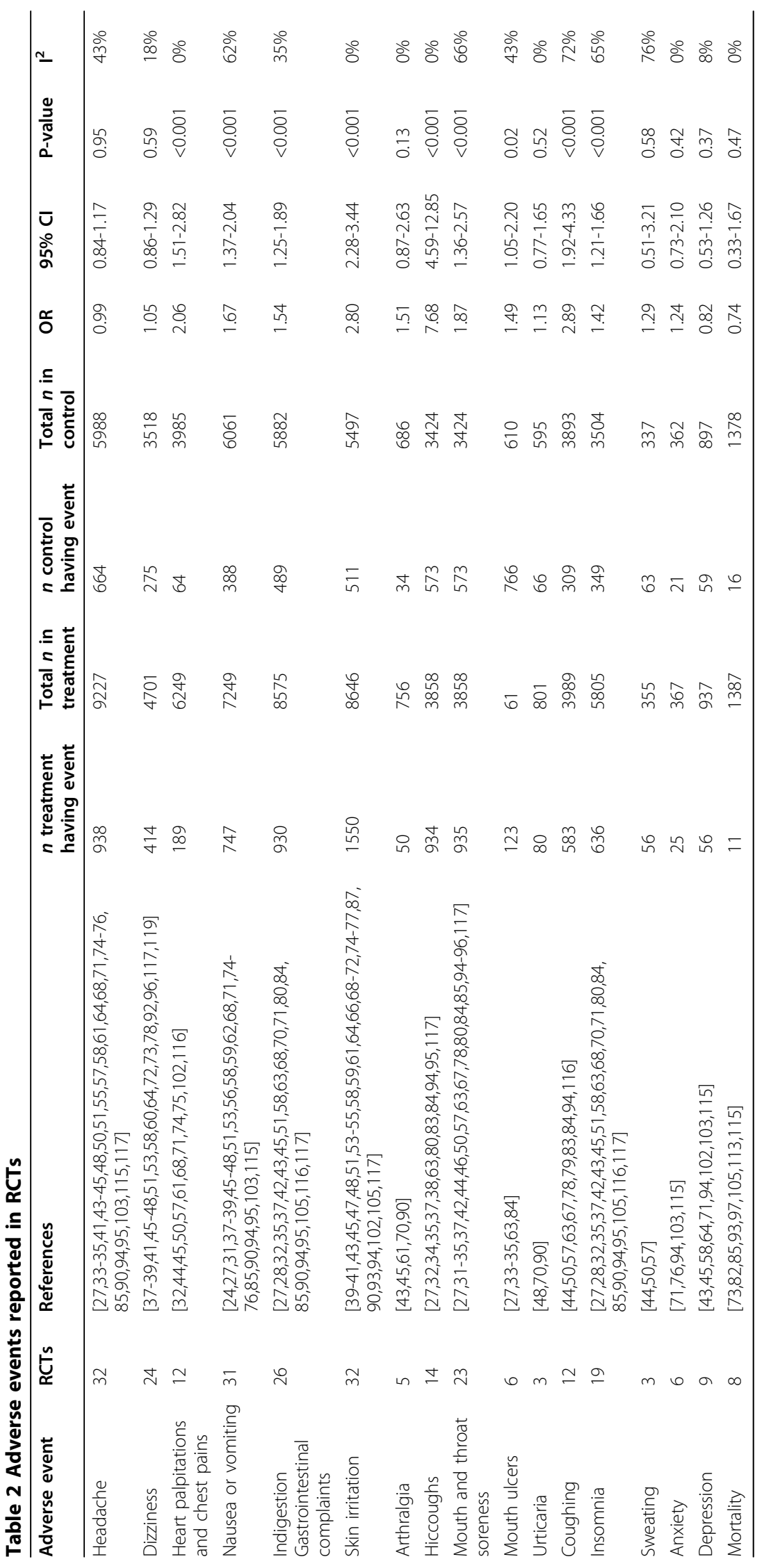


$\mathrm{P}=0.75)$. Coughing was significantly elevated in 12 RCTs (OR 2.89, 95\% CI, 1.92-4.33, P =<0.001; $\mathrm{I}^{2}=72 \%$ ), but was associated with considerable heterogeneity.

\section{Gastrointestinal}

There was a statistically significant increased risk of nausea or vomiting based on a pooled analysis of 31 RCTs (OR 1.67, 95\% CI, 1.37-2.04, P =< 0.001; $\mathrm{I}^{2}=$ $62 \%)$. However, meta-regression showed that studies focusing on the nicotine patch were associated with a decreased risk (OR, 0.73, 95\%, 0.56-0.97, $\mathrm{P}=0.029$ ) of nausea and vomiting. The review also found an increased risk of indigestion and general GI complaints with NRT in an analysis of 26 RCTs (OR 1.54, 95\% CI $\left.1.25-1.89, \mathrm{p}<0.001 ; \mathrm{I}^{2}=35 \%\right)$. Using only orally administered NRT caused significantly greater risk for GI complaints compared with the nicotine patch (OR 1.66, 95\% CI, 1.04-2.63, P = 0.03), and was also associated with an increased risk of hiccoughs (see Table 2).

\section{Oral}

A significantly heightened risk of oral adverse events including mouth and throat soreness was identified in a meta-analysis of 23 RCTs (OR 1.87, 95\% CI, 1.36-2.57, $\left.\mathrm{P}<0.001 ; \mathrm{I}^{2}=66 \%\right)$. A meta-analysis of $6 \mathrm{RCTs}$ found a significantly elevated risk for mouth ulcers (OR 1.49, 95\% CI, 1.05-2.20, P = 0.02; $\mathrm{I}^{2}=43 \%$ ).

\section{Neurological}

A meta-analysis of 32 RCTs (Table 2) found that headache was not associated with NRT use $\left(\mathrm{P}=0.65 ; \mathrm{I}^{2}=\right.$ $43 \%$ ), while an analysis of 24 RCTs, found no association between NRT use and increased dizziness ( $\mathrm{P}=0.59$; $\left.\mathrm{I}^{2}=18 \%\right)$

\section{Dermatological}

Nicotine patch was associated with a statistically significant risk of skin irritation in an analysis of 32 RCTs (OR 2.80, 95\% CI, 2.28-3.44, P $<0.001$; $\mathrm{I}^{2}=0 \%$ ). However, nicotine patch was not associated with increased incidence of urticaria (OR 1.13, 95\% CI, 0.77-1.65, P = $0.52 ; \mathrm{I}^{2}=0 \%$ ) or sweating (OR 1.29, 95\% CI, 0.51-3.21, $\left.\mathrm{P}=0.58 ; \mathrm{I}^{2}=76 \%\right)$.

\section{Psychological}

An increased risk of insomnia was associated with the nicotine patch (OR 1.42, 95\% CI, 1.21-1.66, P < 0.001; $\mathrm{I}^{2}$ $=65 \%)$. Anxiety and depression were, however, not significantly increased (see Table 2).

\section{Serious Adverse Events}

Twenty five RCTs $[47,54,71,73-77,79,80,82,84,85,91$ $93,97,98,100,102,104,105,113,115,142]$ reported serious adverse events occurring, but none were statistically significant (data not shown). Eight studies[73,82,85,93,97, $105,113,115]$ reported on mortality by groups and did not find a significant association between NRT and controls. One study[142] of pregnant women found two cases of spontaneous abortions in the NRT group and one study[76] reported a case of spinal meningitis in the NRT group.

\section{Explanations of heterogeneity}

We used meta-regression to explain heterogeneity. We found large heterogeneity $\left(\mathrm{I}^{2}=62 \%\right)$ in our analysis of pooled events of nausea and vomiting. We were able to explain a large amount of heterogeneity examining the covariate of skin patch vs. oropharyngeal administration (OR 0.73, 95\% CI, 0.56-0.97, P = 0.02, $\mathrm{I}^{2}=42 \%$ ) as well as reporting of allocation concealment (OR 1.50, 95\% $\left.\mathrm{CI}, 1.07-1.59, \mathrm{P}=0.002, \mathrm{I}^{2}=37 \%\right)$. We also found large heterogeneity $\left(\mathrm{I}^{2}=66 \%\right)$ in the event of mouth and throat soreness, but were unable to explain this using our pre-specified covariates. Considerable heterogeneity $\left(\mathrm{I}^{2}=72 \%\right)$ was also identified for the adverse event of coughing. We found that duration of study ( $B$ coefficient $\left.0.07,95 \% \mathrm{CI}, 0.01-0.12, \mathrm{P}=0.01, \mathrm{I}^{2}=42 \%\right)$ and allocation concealment (OR 0.53, 95\% CI, 0.31-0.91, P = $0.02, \mathrm{I}^{2}=43 \%$ ) contributed to heterogeneity observed in this analysis. Our analysis of sweating found large heterogeneity (76\%) that was predominantly contributed by a study that provided concomitant bupropion, indicating that the dual use of both drugs resulted in a significantly higher incidence of sweating (OR 29.24, 95\% CI, 3.96215.48). We also found heterogeneity in our analysis of insomnia that was explained by the duration of the trials. Longer duration trials had reduced rates of insomnia $(B$ coefficient $-0.07,95 \% \mathrm{CI},-0.13$ to $-0.008, \mathrm{p}=$ 0.02).

\section{Observational studies (See Figure 3)}

Table 1 displays the study characteristics of the observational studies. No studies compared NRT with an inert control group, thus we present the proportions of event occurrence, interpreted as prevalence. As our analysis uses pooled proportions, all analyses found an estimate of risk, but varied in magnitude. Table 3 presents the study findings.

\section{Cardiovascular or respiratory}

The prevalence of heart palpitations and chest pains were reported sporadically and amounted to $3.6 \%$ of the populations examined. Coughing was reported as a prevalence of $8.1 \%$.

\section{Gastrointestinal}

In keeping with the RCT evidence indicating significant increases in specific events, the pooled observational evidence reported the nausea and vomiting prevalence to be $8.5 \%$ amongst individuals in the community treated with NRT. The prevalence of indigestion and other gastrointestinal complaints was $3.9 \%$. Hiccoughs were a very common complaint in the RCT evidence, but poorly reported in the observational studies with a prevalence of just $2.5 \%$. 


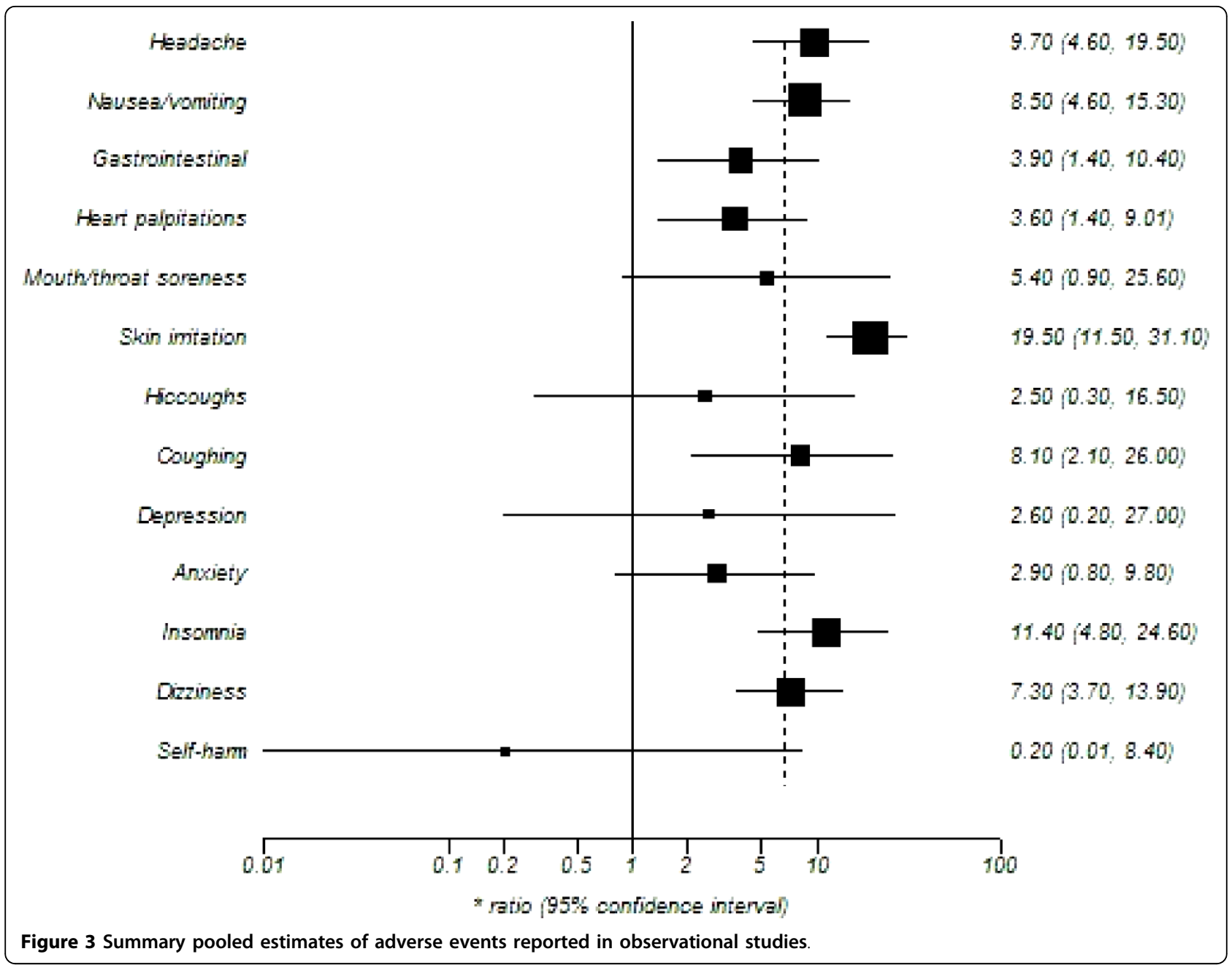

Table 3 Adverse events reported in observational studies

\begin{tabular}{|c|c|c|c|c|c|c|c|}
\hline Adverse event & $\begin{array}{l}\text { Number } \\
\text { of studies }\end{array}$ & References & $\mathrm{N}$ of events & Pooled $n$ & Proportion & $95 \% \mathrm{Cl}$ & $\tau^{2}$ \\
\hline Headache & 17 & {$[75,93,110,118-120,123-125,127-129,131,136,138,140,141]$} & 1472 & 75764 & 9.7 & $4.6-19.5$ & 2.97 \\
\hline $\begin{array}{l}\text { Nausea or } \\
\text { vomiting }\end{array}$ & 14 & {$[75,110,119,120,123,124,128,129,136-138,140,141]$} & 1902 & 74449 & 8.5 & 4.6-15.3 & 1.39 \\
\hline $\begin{array}{l}\text { Gastrointestinal } \\
\text { complaints }\end{array}$ & 11 & {$[110,118,120,123,127,129,131,136,138,140,141]$} & 593 & 74256 & 3.9 & $1.4-10.4$ & 3.02 \\
\hline $\begin{array}{l}\text { Heart } \\
\text { palpitations }\end{array}$ & 7 & {$[75,120,122,127,131,136,141]$} & 72 & 2446 & 3.6 & $1.4-9.0$ & 1.49 \\
\hline $\begin{array}{l}\text { Mouth and } \\
\text { throat soreness }\end{array}$ & 6 & {$[125,129,135-137,140]$} & 406 & 72533 & 5.4 & $0.9-25.6$ & 5.00 \\
\hline Skin irritation & 16 & {$[75,93,118-124,126-129,131,138,141]$} & 1337 & 10356 & 19.5 & $11.5-31.1$ & 1.56 \\
\hline Hiccoughs & 4 & {$[129,136,137,140]$} & 375 & 71948 & 2.5 & $0.3-16.5$ & 4.63 \\
\hline Coughing & 5 & {$[120,125,128,135,136]$} & 125 & 1672 & 8.1 & $2.1-26$ & 2.29 \\
\hline Depression & 6 & {$[110,120,124,138,140,141]$} & 69 & 66344 & 2.6 & $0.2-27$ & 10.57 \\
\hline Anxiety & 5 & {$[118,120,129,138,141]$} & 104 & 5841 & 2.9 & $0.8-9.8$ & 1.70 \\
\hline Insomnia & 18 & {$[75,110,118-123,125-129,131,138,140,141]$} & 2262 & 76169 & 11.4 & 4.8-24.6 & 4.05 \\
\hline Dizziness & 8 & {$[110,118,120,124,127,129,136,141]$} & 299 & 7338 & 7.3 & $3.7-13.9$ & 0.94 \\
\hline Self-harm & 1 & {$[110,118,120,124,127,129,136,141]$} & 141 & 63265 & 0.2 & $0-8.4$ & NA \\
\hline
\end{tabular}




\section{Oral}

With orally administered NRT, the prevalence of both mouth and throat soreness was $5.4 \%$.

\section{Psychological and neurological}

For psychological complaints, the prevalence of insomnia was $11.4 \%$. Anxiety and depression were more rarely reported ( $2.9 \%$ and $2.6 \%$ respectively). Dizziness was a more common complaint, with a prevalence of $7.3 \%$. Headaches were commonly reported (9.7\%).

\section{Dermatological}

The prevalence of skin irritations associated with nicotine patch was reported as $19.5 \%$ of the populations examined.

\section{Serious adverse events}

Serious adverse events were poorly reported in the observational studies. However, one study reported on a case of transient visual field impairment; one righthemisphere stroke; one myocardial infraction; and one urticarial reaction from skin patch with symptoms of angiodema. Finally, in a single large observational study of self-harm ( $n=63,265), 141$ cases of fatal and nonfatal self-harm cases were identified $(0.2 \%)$, in addition to 30 cases of suicidal ideation[139].

\section{Discussion}

\section{Principal Findings}

This review found that NRT is associated with an increased risk of gastrointestinal complaints and insomnia. There was also an observed increased risk of skin irritation with the nicotine patch and oropharyngeal complaints with orally administered NRT. Although NRT was associated with an increased risk of heart palpitations, the review did not observe an increased incident of heart attack or death. With the exception of insomnia, NRT does not appear to be associated with serious adverse psychiatric effects.

The reviewers actively sought serious adverse events. The most serious adverse event consistently reported in both RCTs and observational studies were heart palpitations and chest pains (OR 2.06, 95\% CI, 1.51-2.82, $\mathrm{P}<$ $0.001)$. NRT has been implicated in reports of atrial fibrillation and myocardial infarction among patients with risk factors[143-148]. Several possible explanations for this exist. First, among patients using NRT who continue to smoke, high serum concentrations may stimulate the sympathetic nervous system, so increasing blood pressure, stroke volume and cardiac output[149]. Second, previous and current smokers may have established cardiovascular disease. Patients with unstable coronary syndrome, a common manifestation of coronary artery disease, may have unrecognized recent plaque ruptures including coronary vasoconstriction and increased strain placed on the heart due to tachycardia and hypertension [143]. Unofficial guidelines[149] caution the continued use of NRT in patients with known cardiovascular disease in the absence of a physician. They recommend that patients be warned of these risks and counseled to desist smoking and arrange intensive behavioral support [149]. In our analysis, we did not observe an increased risk for myocardial infarction or death from NRT.

Almost all studies demonstrated localized irritation related to NRT use, skin irritation with the use of NRT patch and mouth soreness and ulcerations with orally administered NRT. It is possible this is due to the success of cessation rather than NRT as mouth ulcers occur in about $40 \%$ of all individuals achieving tobacco abstinence regardless of cessation intervention[150]. It has previously been understood that mouth lesions are associated with smoking cessation and not NRT[150]. However, this review found a significantly increased risk of mouth ulcers with orally administered NRT users compared to inert controls who had ceased smoking. In order to prevent relapse due to treatment discontinuation, strategies should be developed to assist patients unable to continue oral administered NRT due to mouth ulcers such as increasing the nicotine patch dose, using the nicotine nasal spray, or switching to an alternative form of smoking cessation pharmacotherapy such as buproprion or varenicline.

Psychological adverse events, particularly suicidal ideation, are a major concern in patients initiating smoking cessation[151]. We found only one large retrospective observational study that discussed this topic and reported no significant difference in fatal and non-fatal self-harm associated with NRT compared to other frequently used pharmacotherapies, bupropion (HR 1.17, 95\% CI, 0.59-2.32) or varenicline (HR 1.12, 95\% CI, $0.67-1.88)$ [139].

A criticism of smoking cessation trials has been that they infrequently enroll participants with psychological difficulties, thus making generalizable statements about their safety difficult[152]. The present review found that 56 RCTs specifically excluded participants with mental disorders. Only two RCTs targeting participants with concomitant psychological difficulties, specifically alcoholism and depression, were identified $[89,92]$. In these studies, the risk of insomnia was higher among those taking NRT, compared to controls, (OR 1.42, 95\% CI, $1.21-1.66, \mathrm{P}<0.001)$. Sleep disturbance can significantly worsen psychological distress and mental illness and impair quality of life[153]. Therefore, clinicians should remain vigilant about NRT-related sleep disturbance among patients with a history of psychiatric illness.

An important issue to examine when describing adverse events from smoking cessation therapies is whether the adverse events are related to a pharmacotherapy or whether they are related to tobacco withdrawal[154]. For example, insomnia and sleep 
disturbances could be related to tobacco abstinence. One way to assess this affect would be to compare side effects in those that have quit smoking in both groups. However, since individuals that quit smoking may differ from those that continue, this analysis would remove the benefits of randomization and introduce bias.

\section{Limitations}

Our review has several limitations. These include limitations of the primary studies themselves as well as those associated with combining results across potentially heterogeneous studies or populations. The main limitation of the primary studies is the mechanism by which adverse events are recorded. In the majority of instances this would be through passive reporting and therefore be susceptible to the underreporting associated with such techniques. The majority of our analyses had low or moderate heterogeneity, although a few had high levels of heterogeneity. Pooling proportions always results in large estimates of heterogeneity and statistical techniques do not yet exist to interpret the extent of real between-study heterogeneity[155]. The review identified some discrepancies between observational studies and RCTs in terms of adverse event reporting. Possible explanations of this include the use of a control group in the RCTs, which diminishes the impact of adverse events that are, in fact, unrelated to the intervention. Studies included in our review varied in the duration of treatment phase. While we would expect most adverse events to occur during the treatment phase (receiving active NRT), it is possible that some adverse events occurred during follow-up and we cannot adequately explain their pathological processes.

There is emerging evidence that stopping smoking prior to any type of surgery decreases the potential for surgical complications[156]. All pharmacotherapies used for smoking cessation demonstrate adverse events, albeit in differing conditions and severity[4]. However, given the cardiovascular concerns discussed above, and the fact that cardiovascular events are increased during the perioperative period[157], it is reasonable to consider other behavioral or pharmacotherapies for at-risk patients undergoing major surgeries.

\section{Conclusions}

This review demonstrates that NRT is associated with adverse effects that may be discomforting for the patient but are not life-threatening. Given the long-term benefits of smoking cessation over continued smoking, concern about NRT related adverse events should be balanced against the benefits of cessation. Clinicians should monitor for side effects that may worsen underlying conditions, such as insomnia in patients with depression, and consider additional or alternative treatments. Given the benefits of smoking cessation and the important role of NRT in achieving this goal, efforts should be made to counsel patients on the most common side effects and strategies should be developed to deal with them.

\section{Additional material}

Additional file 1: Characteristics of included RCTs. CVD,

cardiovascular; $\mathrm{RCT}$, randomized clinical trial

\section{Author details}

${ }^{1}$ Faculty of Health Sciences, University of Ottawa, Ottawa, Canada. ${ }^{2}$ Department of Epidemiology, London School of Hygiene \& Tropical Medicine, London, UK. ${ }^{3}$ Pfizer Limited, Tadworth, Surrey, UK. ${ }^{4}$ Ottawa Health Research Institute, Ottawa, Canada. ${ }^{5}$ Mayo Graduate School of Medicine, Mayo Clinic, Rochester, MN, USA.

\section{Authors' contributions}

EM, PW, IL, KW conceived the study. EM, PW carried out searches and data abstraction. EM, PW, IL, KW, JE were involved in data analysis. EM, PW, IL, KW, JE contributed to manuscript drafting and interpretation of data. All authors read and approved the final draft.

\section{Competing interests}

Pfizer Ltd. Walton Oaks, Walton-On-The-Hill, Surrey, KT20 7NS, United Kingdom, sponsored development of the review and manuscript. Edward Mills and Ping Wu were paid consultants to Pfizer in connection with the development of this manuscript. Kumanan Wilson and Job O. Ebbert received no compensation. lan Lockhart is an employee of Pfizer.

Received: 21 January 2010 Accepted: 13 July 2010

Published: 13 July 2010

\section{References}

1. Peto R, Lopez AD, Boreham J, Thun M, Heath C Jr, Doll R: Mortality from smoking worldwide. Br Med Bull 1996, 52:12-21.

2. Doll $R$, Peto $R$, Wheatley $K$, Gray $R$, Sutherland I: Mortality in relation to smoking: 40 years' observations on male British doctors. Bmj 1994, 309:901-11.

3. Asaria P, Chisholm D, Mathers C, Ezzati M, Beaglehole R: Chronic disease prevention: health effects and financial costs of strategies to reduce salt intake and control tobacco use. Lancet 2007, 370:2044-53.

4. Wu P, Wilson K, Dimoulas P, Mills EJ: Effectiveness of smoking cessation therapies: a systematic review and meta-analysis. BMC Public Health 2006, 6:300.

5. NICE: Smoking cessation services in primary care, pharmacies, local authorities and workplaces, particularly for manual working groups, pregnant women and hard to reach communities. Public Health Guidance PH10. 2008 [http://www.nice.org.uk/guidance/index.jsp? action=by|D\&o=11925].

6. Eisenberg MJ, Filion KB, Yavin D, Belisle P, Mottillo S, Joseph L, et al: Pharmacotherapies for smoking cessation: a meta-analysis of randomized controlled trials. Cmaj 2008, 179:135-44.

7. Vjogt F, Hall S, Marteau TM: Understanding why smokers do not want to use nicotine dependence medications to stop smoking: qualitative and quantitative studies. Nicotine Tob Res 2008, 10:1405-13.

8. Hughes JR: Effects of abstinence from tobacco: valid symptoms and time course. Nicotine Tob Res 2007, 9:315-27.

9. Chou $\mathrm{R}$, Helfand $\mathrm{M}$ : Challenges in systematic reviews that assess treatment harms. Ann Intern Med 2005, 142:1090-9.

10. Kuper $\mathrm{H}$, Nicholson $\mathrm{A}$, Hemingway $\mathrm{H}$ : Searching for observational studies: what does citation tracking add to PubMed? A case study in depression and coronary heart disease. BMC medical research methodology 2006, 6:4.

11. Tonnesen P: Smoking cessation: How compelling is the evidence? A review. Health policy (Amsterdam, Netherlands) 2009, 91(Suppl 1):S15-25. 
12. Mills EJ, Wu P, Spurden D, Ebbert JO, Wilson K: Efficacy of pharmacotherapies for short-term smoking abstinance: A systematic review and meta-analysis. Harm Reduct J 2009, 6:25.

13. Stead LF, Perera R, Bullen C, Mant D, Lancaster T: Nicotine replacement therapy for smoking cessation. Cochrane database of systematic reviews (Online) 2008, CD000146.

14. Stead LF, Lancaster T: Interventions to reduce harm from continued tobacco use. Cochrane database of systematic reviews (Online) 2007, CD005231.

15. Cahill K, Stead LF, Lancaster T: Nicotine receptor partial agonists for smoking cessation. Cochrane database of systematic reviews (Online) 2007, CD006103

16. Woolacott NF, Jones L, Forbes CA, Mather LC, Sowden AJ, Song FJ, et al: The clinical effectiveness and cost-effectiveness of bupropion and nicotine replacement therapy for smoking cessation: a systematic review and economic evaluation. Health technology assessment (Winchester, England) 2002, 6:1-245

17. Meade MO, Guyatt GH, Cook RJ, Groll R, Kachura JR, Wigg M, et al: Agreement between alternative classifications of acute respiratory distress syndrome. Am J Respir Crit Care Med 2001, 163:490-3.

18. Sheehe PR: Combination of log relative risk in retrospective studies of disease. Am J Public Health Nations Health 1966, 56:1745-50.

19. DerSimonian R, Laird N: Meta-analysis in clinical trials. Control Clin Trials 1986, 7:177-88.

20. Fleiss JL: The statistical basis of meta-analysis. Stat Methods Med Res 1993, 2:121-45.

21. Higgins JP, Thompson SG: Quantifying heterogeneity in a meta-analysis. Stat Med 2002, 21:1539-58.

22. Stuart A, Ord JK: Kendall's Advanced Theory of Statistics. London: Edward Arnold, 61994.

23. Borenstin $M$, Hedges L, Higgins JP, Rothstein $\mathrm{H}$ : Introduction to Metaanalysis. Wiley, Chichester 2009, 312.

24. Mills EJ, Nachega JB, Bangsberg DR, Singh S, Rachlis B, Wu P, et al: Adherence to HAART: a systematic review of developed and developing nation patient-reported barriers and facilitators. PLoS medicine 2006, 3 e438.

25. Rucker G, Schwarzer G, Carpenter JR, Schumacher M: Undue reliance on I (2) in assessing heterogeneity may mislead. BMC medical research methodology 2008, 8:79.

26. Malcolm RE, Sillett RW, Turner JA, Ball KP: The use of nicotine chewing gum as an aid to stopping smoking. Psychopharmacology (Berl) 1980, 70:295-6.

27. Jarvis MJ, Raw M, Russell MA, Feyerabend C: Randomised controlled trial of nicotine chewing-gum. Br Med J (Clin Res Ed) 1982, 285:537-40.

28. Fagerstrom KO: A comparison of psychological and pharmacological treatment in smoking cessation. J Behav Med 1982, 5:343-51.

29. Comparison of four methods of smoking withdrawal in patients with smoking related diseases. Report by a subcommittee of the Research Committee of the British Thoracic Society. Br Med J (Clin Res Ed) 1983, 286:595-7.

30. Schneider NG, Jarvik ME, Forsythe AB, Read LL, Elliott ML, Schweiger A: Nicotine gum in smoking cessation: a placebo-controlled, double-blind trial. Addict Behav 1983, 8:253-61.

31. Jamrozik K, Fowler G, Vessey M, Wald N: Placebo controlled trial of nicotine chewing gum in general practice. Br Med I (Clin Res Ed) 1984, 289:794-7.

32. Tonnesen $\mathrm{P}$, Fryd $\mathrm{V}$, Hansen $\mathrm{M}$, Helsted J, Gunnersen AB, Forchammer $\mathrm{H}$, et al: Two and four mg nicotine chewing gum and group counselling in smoking cessation: an open, randomized, controlled trial with a 22 month follow-up. Addict Behav 1988, 13:17-27.

33. Areechon W, Punnotok J: Smoking cessation through the use of nicotine chewing gum: a double-blind trial in Thailand. Clin Ther 1988, 10:183-6.

34. Fortmann SP, Killen JD, Telch MJ, Newman B: Minimal contact treatment for smoking cessation. A placebo controlled trial of nicotine polacrilex and self-directed relapse prevention: initial results of the Stanford Stop Smoking Project. Jama 1988, 260:1575-80.

35. Harackiewicz JM, Blair LW, Sansone C, Epstein JA, Stuchell RN: Nicotine gum and self-help manuals in smoking cessation: an evaluation in a medical context. Addict Behav 1988, 13:319-30.
36. Tonnesen P, Fryd V, Hansen M, Helsted J, Gunnersen AB, Forchammer $H$, et al: Effect of nicotine chewing gum in combination with group counseling on the cessation of smoking. N Engl J Med 1988, 318:15-8.

37. Hughes JR, Gust SW, Keenan RM, Fenwick JW, Healey ML: Nicotine vs placebo gum in general medical practice. Jama 1989, 261:1300-5.

38. Blondal T: Controlled trial of nicotine polacrilex gum with supportive measures. Arch Intern Med 1989, 149:1818-21.

39. Abelin T, Ehrsam R, Buhler-Reichert A, Imhof PR, Muller P, Thommen A, et al: Effectiveness of a transdermal nicotine system in smoking cessation studies. Methods Find Exp Clin Pharmacol 1989, 11:205-14.

40. Hurt RD, Lauger GG, Offord KP, Kottke TE, Dale LC: Nicotine-replacement therapy with use of a transdermal nicotine patch-a randomized doubleblind placebo-controlled trial. Mayo Clin Proc 1990, 65:1529-37.

41. Tonnesen P, Norregaard J, Simonsen K, Sawe U: A double-blind trial of a 16-hour transdermal nicotine patch in smoking cessation. N Engl J Med 1991, 325:311-5.

42. Campbell IA, Prescott RJ, Tjeder-Burton SM: Smoking cessation in hospital patients given repeated advice plus nicotine or placebo chewing gum. Respir Med 1991, 85:155-7.

43. Daughton DM, Heatley SA, Prendergast JJ, Causey D, Knowles M, Rolf CN, et al: Effect of transdermal nicotine delivery as an adjunct to lowintervention smoking cessation therapy. A randomized, placebocontrolled, double-blind study. Arch Intern Med 1991, 151:749-52.

44. Sutherland G, Stapleton JA, Russell MA, Jarvis MJ, Hajek P, Belcher M, et al: Randomised controlled trial of nasal nicotine spray in smoking cessation. Lancet 1992, 340:324-9.

45. Sachs DP, Sawe U, Leischow SJ: Effectiveness of a 16-hour transdermal nicotine patch in a medical practice setting, without intensive group counseling. Arch Intern Med 1993, 153:1881-90.

46. Tonnesen P, Norregaard J, Mikkelsen K, Jorgensen S, Nilsson F: A doubleblind trial of a nicotine inhaler for smoking cessation. Jama 1993, 269:1268-71.

47. Merz PG, Keller-Stanislawski B, Huber T, Woodcock BG, Rietbrock N: Transdermal nicotine in smoking cessation and involvement of nonspecific influences. Int I Clin Pharmacol Ther Toxicol 1993, 31:476-82.

48. Russell MA, Stapleton JA, Feyerabend C, Wiseman SM, Gustavsson G, Sawe $U$, et al: Targeting heavy smokers in general practice: randomised controlled trial of transdermal nicotine patches. $B m j$ 1993, 306:1308-12.

49. Westman EC, Levin ED, Rose JE: The nicotine patch in smoking cessation. A randomized trial with telephone counseling. Arch Intern Med 1993, 153:1917-23.

50. Hjalmarson A, Franzon M, Westin A, Wiklund O: Effect of nicotine nasal spray on smoking cessation. A randomized, placebo-controlled, doubleblind study. Arch Intern Med 1994, 154:2567-72.

51. Hurt RD, Dale LC, Fredrickson PA, Caldwell CC, Lee GA, Offord KP, et al: Nicotine patch therapy for smoking cessation combined with physician advice and nurse follow-up. One-year outcome and percentage of nicotine replacement. Jama 1994, 271:595-600.

52. Fiore MC, Kenford SL, Jorenby DE, Wetter DW, Smith SS, Baker TB: Two studies of the clinical effectiveness of the nicotine patch with different counseling treatments. Chest 1994, 105:524-33.

53. Richmond RL, Harris K, de Almeida Neto A: The transdermal nicotine patch: results of a randomised placebo-controlled trial. Med J Aust 1994, 161:130-5.

54. Levin ED, Westman EC, Stein RM, Carnahan E, Sanchez M, Herman S, et al: Nicotine skin patch treatment increases abstinence, decreases withdrawal symptoms, and attenuates rewarding effects of smoking. J Clin Psychopharmacol 1994, 14:41-9.

55. Stapleton JA, Russell MA, Feyerabend C, Wiseman SM, Gustavsson G, Sawe $U$, et al: Dose effects and predictors of outcome in a randomized trial of transdermal nicotine patches in general practice. Addiction 1995 90:31-42.

56. Herrera N, Franco R, Herrera L, Partidas A, Rolando R, Fagerstrom KO: Nicotine gum, 2 and $4 \mathrm{mg}$, for nicotine dependence. A double-blind placebo-controlled trial within a behavior modification support program. Chest 1995, 108:447-51.

57. Schneider NG, Olmstead R, Mody FV, Doan K, Franzon M, Jarvik ME, et al: Efficacy of a nicotine nasal spray in smoking cessation: a placebocontrolled, double-blind trial. Addiction 1995, 90:1671-82. 
58. Puska PKH, Vartiainen E, Urjanheimo E: Combined use of nicotine patch and gum compared with gum alone in smoking cessation: a clinical trial in North Karelia. Tabacco Control 1995, 4:231-5.

59. Kornitzer M, Boutsen M, Dramaix M, Thijs J, Gustavsson G: Combined use of nicotine patch and gum in smoking cessation: a placebo-controlled clinical trial. Prev Med 1995, 24:41-7.

60. Dale LC, Hurt RD, Offord KP, Lawson GM, Croghan IT, Schroeder DR: Highdose nicotine patch therapy. Percentage of replacement and smoking cessation. Jama 1995, 274:1353-8.

61. Gourlay SG, Forbes A, Marriner T, Pethica D, McNeil JJ: Double blind trial of repeated treatment with transdermal nicotine for relapsed smokers. Bmj 1995, 311:363-6

62. Leischow SJN, Franzo F, Hill M, Otte A, Merikle P, E P: Efficacy of the Nicotine Inhaler as an Adjunct to Smoking Cessation. American Journal of Health Behavior 1996, 20:364-71.

63. Schneider NG, Olmstead R, Nilsson F, Mody FV, Franzon M, Doan K: Efficacy of a nicotine inhaler in smoking cessation: a double-blind, placebocontrolled trial. Addiction 1996, 91:1293-306.

64. Paoletti P, Fornai E, Maggiorelli F, Puntoni R, Viegi G, Carrozzi L, et al: Importance of baseline cotinine plasma values in smoking cessation: results from a double-blind study with nicotine patch. Eur Respir J 1996, 9:643-51.

65. Blondal $\mathrm{T}$, Franzon $\mathrm{M}$, Westin $\mathrm{A}$ : A double-blind randomized trial of nicotine nasal spray as an aid in smoking cessation. Eur Respir J 1997, 10:1585-90.

66. Campbell IA, Prescott RJ, Tjeder-Burton SM: Transdermal nicotine plus support in patients attending hospital with smoking-related diseases: a placebo-controlled study. Respir Med 1996, 90:47-51.

67. Hjalmarson A, Nilsson F, Sjostrom L, Wiklund O: The nicotine inhaler in smoking cessation. Arch Intern Med 1997, 157:1721-8.

68. Sonderskov J, Olsen J, Sabroe S, Meillier L, Overvad K: Nicotine patches in smoking cessation: a randomized trial among over-the-counter customers in Denmark. Am J Epidemio/ 1997, 145:309-18.

69. Perng RP, Hsieh WC, Chen YM, Lu CC, Chiang SJ: Randomized, doubleblind, placebo-controlled study of transdermal nicotine patch for smoking cessation. J Formos Med Assoc 1998, 97:547-51.

70. Ahluwalia JS, MCNagny SE, Clark WS: Smoking cessation among inner-city African Americans using the nicotine transdermal patch. J Gen Intern Med 1998, 13:1-8.

71. Lewis SF, Piasecki TM, Fiore MC, Anderson JE, Baker TB: Transdermal nicotine replacement for hospitalized patients: a randomized clinical trial. Prev Med 1998, 27:296-303

72. Davidson M, Epstein M, Burt R, Schaefer C, Whitworth G, McDonald A: Efficacy and safety of an over-the-counter transdermal nicotine patch as an aid for smoking cessation. Arch Fam Med 1998, 7:569-74

73. Blondal T, Gudmundsson LJ, Olafsdottir I, Gustavsson G, Westin A: Nicotine nasal spray with nicotine patch for smoking cessation: randomised trial with six year follow up. Bmj 1999, 318:285-8.

74. Tonnesen P, Paoletti P, Gustavsson G, Russell MA, Saracci R, Gulsvik A, et al: Higher dosage nicotine patches increase one-year smoking cessation rates: results from the European CEASE trial. Collaborative European Anti-Smoking Evaluation. European Respiratory Society. Eur Respir J 1999, 13:238-46.

75. Hays JT, Croghan IT, Schroeder DR, Offord KP, Hurt RD, Wolter TD, et al: Over-the-counter nicotine patch therapy for smoking cessation: results from randomized, double-blind, placebo-controlled, and open label trials. Am J Public Health 1999, 89:1701-7.

76. Jorenby DE, Leischow SJ, Nides MA, Rennard SI, Johnston JA, Hughes AR, et al: A controlled trial of sustained-release bupropion, a nicotine patch, or both for smoking cessation. N Engl J Med 1999, 340:685-91.

77. Bohadana A, Nilsson F, Rasmussen T, Martinet Y: Nicotine inhaler and nicotine patch as a combination therapy for smoking cessation: a randomized, double-blind, placebo-controlled trial. Arch Intern Med 2000, 160:3128-34.

78. Bolliger CT, Zellweger JP, Danielsson T, van Biljon X, Robidou A, Westin $A$, et al: Smoking reduction with oral nicotine inhalers: double blind, randomised clinical trial of efficacy and safety. Bmj 2000, 321:329-33

79. Garvey AJ, Kinnunen T, Nordstrom BL, Utman CH, Doherty $\mathrm{K}$, Rosner B, et al: Effects of nicotine gum dose by level of nicotine dependence. Nicotine Tob Res 2000, 2:53-63.
80. Wallstrom M, Nilsson F, Hirsch JM: A randomized, double-blind, placebocontrolled clinical evaluation of a nicotine sublingual tablet in smoking cessation. Addiction 2000, 95:1161-71.

81. Wisborg K, Henriksen TB, Jespersen LB, Secher NJ: Nicotine patches for pregnant smokers: A randomized controlled study. Obstet Gynecol 2000 96:967-71

82. Etter JF, Laszlo E, Zellweger JP, Perrot C, Perneger TV: Nicotine replacement to reduce cigarette consumption in smokers who are unwilling to quit: a randomized trial. J Clin Psychopharmacol 2002, 22:487-95

83. Shiffman S, Gorsline J, Gorodetzky CW: Efficacy of over-the-counter nicotine patch. Nicotine Tob Res 2002, 4:477-83.

84. Glover ED, Glover PN, Franzon M, Sullivan CR, Cerullo CC, Howell RM, et al: A comparison of a nicotine sublingual tablet and placebo for smoking cessation. Nicotine Tob Res 2002, 4:441-50.

85. Shiffman S, Dresler CM, Hajek P, Gilburt SJ, Targett DA, Strahs KR: Efficacy of a nicotine lozenge for smoking cessation. Arch Intern Med 2002, 162:1267-76.

86. Hand S, Edwards S, Campbell IA, Cannings R: Controlled trial of three weeks nicotine replacement treatment in hospital patients also given advice and support. Thorax 2002, 57:715-8.

87. Glavas D, Rumboldt M, Rumboldt Z: Smoking cessation with nicotine replacement therapy among health care workers: randomized doubleblind study. Croat Med J 2003, 44:219-24.

88. Wennike P, Danielsson T, Landfeldt B, Westin A, Tonnesen P: Smoking reduction promotes smoking cessation: results from a double blind, randomized, placebo-controlled trial of nicotine gum with 2-year followup. Addiction 2003, 98:1395-402.

89. Hughes JR, Novy P, Hatsukami DK, Jensen J, Callas PW: Efficacy of nicotine patch in smokers with a history of alcoholism. Alcohol Clin Exp Res 2003, 27:946-54.

90. Hanson K, Allen S, Jensen S, Hatsukami D: Treatment of adolescent smokers with the nicotine patch. Nicotine Tob Res 2003, 5:515-26.

91. Molyneux A, Lewis S, Leivers U, Anderton A, Antoniak M, Brackenridge A, et al: Clinical trial comparing nicotine replacement therapy (NRT) plus brief counselling, brief counselling alone, and minimal intervention on smoking cessation in hospital inpatients. Thorax 2003, 58:484-8.

92. Smith SS, Jorenby DE, Leischow SJ, Nides MA, Rennard SI, Johnston JA et al: Targeting smokers at increased risk for relapse: treating women and those with a history of depression. Nicotine Tob Res 2003, 5:99-109.

93. Schuurmans MM, Diacon AH, van Biljon X, Bolliger CT: Effect of pretreatment with nicotine patch on withdrawal symptoms and abstinence rates in smokers subsequently quitting with the nicotine patch: a randomized controlled trial. Addiction 2004, 99:634-40.

94. Moolchan ET, Robinson ML, Ernst M, Cadet JL, Pickworth WB, Heishman SJ, et al: Safety and efficacy of the nicotine patch and gum for the treatment of adolescent tobacco addiction. Pediatrics 2005, 115:e407-14.

95. Batra A, Klingler $K$, Landfeldt B, Friederich HM, Westin A, Danielsson T: Smoking reduction treatment with 4-mg nicotine gum: a double-blind, randomized, placebo-controlled study. Clin Pharmacol Ther 2005, 78:689-96.

96. Rennard SI, Glover ED, Leischow S, Daughton DM, Glover PN, Muramoto M, et al: Efficacy of the nicotine inhaler in smoking reduction: A doubleblind, randomized trial. Nicotine Tob Res 2006, 8:555-64.

97. Tonnesen P, Mikkelsen K, Bremann L: Nurse-conducted smoking cessation in patients with COPD using nicotine sublingual tablets and behavioral support. Chest 2006, 130:334-42.

98. Hotham ED, Gilbert AL, Atkinson ER: A randomised-controlled pilot study using nicotine patches with pregnant women. Addict Behav 2006, 31:641-8.

99. Myung SK, Seo HG, Park S, Kim Y, Kim DJ, Lee do H, et al: Sociodemographic and smoking behavioral predictors associated with smoking cessation according to follow-up periods: a randomized, double-blind, placebo-controlled trial of transdermal nicotine patches. $J$ Korean Med Sci 2007, 22:1065-70.

100. Covey LS, Glassman AH, Jiang H, Fried J, Masmela J, LoDuca C, et al: A randomized trial of bupropion and/or nicotine gum as maintenance treatment for preventing smoking relapse. Addiction 2007, 102:1292-302.

101. Piper ME, Federman EB, MCCarthy DE, Bolt DM, Smith SS, Fiore MC, et al: Efficacy of bupropion alone and in combination with nicotine gum. Nicotine Tob Res 2007, 9:947-54 
102. Oncken C, Cooney J, Feinn R, Lando H, Kranzler HR: Transdermal nicotine for smoking cessation in postmenopausal women. Addict Behav 2007, 32:296-309.

103. Uyar M, Filiz A, Bayram N, Elbek O, Herken H, Topcu A, et al: A randomized trial of smoking cessation. Medication versus motivation. Saudi Med J 2007, 28:922-6.

104. Pollak KI, Oncken CA, Lipkus IM, Lyna P, Swamy GK, Pletsch PK, et al: Nicotine replacement and behavioral therapy for smoking cessation in pregnancy. Am J Prev Med 2007, 33:297-305.

105. Joseph AM, Norman SM, Ferry LH, Prochazka AV, Westman EC, Steele BG, et al: The safety of transdermal nicotine as an aid to smoking cessation in patients with cardiac disease. N Engl J Med 1996, 335:1792-8.

106. Buchkremer $G$, Bents $H$, Minneker $E$, Opitz K: Long-term effects of a combination of transdermal nicotine administration with behavior therapy for smoking cessation. Nervenarzt 1988, 59:488-90.

107. Transdermal nicotine for smoking cessation. Six-month results from two multicenter controlled clinical trials. Transdermal Nicotine Study Group. Jama 1991, 266:3133-8.

108. Jensen EJ, Schmidt E, Pedersen B, Dahl R: Effect of nicotine, silver acetate, and ordinary chewing gum in combination with group counselling on smoking cessation. Thorax 1990, 45:831-4

109. Hughes JR, Gust SW, Keenan RM, Fenwick JW: Effect of dose on nicotine's reinforcing, withdrawal-suppression and self-reported effects. $J$ Pharmacol Exp Ther 1990, 252:1175-83.

110. Aubin HJ, Bobak A, Britton JR, Oncken C, Billing CB Jr, Gong J, et al: Varenicline versus transdermal nicotine patch for smoking cessation: results from a randomised open-label trial. Thorax 2008, 63:717-24.

111. Rubinstein ML, Benowitz NL, Auerback GM, Moscicki AB: A randomized trial of nicotine nasal spray in adolescent smokers. Pediatrics 2008, 122: e595-600.

112. Warner DO, Patten CA, Ames SC, Offord KP, Schroeder DR: Effect of nicotine replacement therapy on stress and smoking behavior in surgical patients. Anesthesiology 2005, 102:1138-46.

113. Murray RP, Bailey WC, Daniels K, Bjornson WM, Kurnow K, Connett JE, et al: Safety of nicotine polacrilex gum used by 3,094 participants in the Lung Health Study. Lung Health Study Research Group. Chest 1996, 109:438-45.

114. Sun $H Q$, Guo S, Chen DF, Jiang ZN, Liu Y, Di XL, et al: Family support and employment as predictors of smoking cessation success: a randomized, double-blind, placebo-controlled trial of nicotine sublingual tablets in chinese smokers. Am J Drug Alcohol Abuse 2009, 35:183-8.

115. Rigotti NA, Gonzales D, Dale LC, Lawrence D, Chang Y: A randomized controlled trial of adding the nicotine patch to rimonabant for smoking cessation: efficacy, safety and weight gain. Addiction 2009, 104:266-76.

116. Shiffman S, Ferguson SG, Strahs KR: Quitting by gradual smoking reduction using nicotine gum: a randomized controlled trial. Am J Prev Med 2009, 36:96-104, e1.

117. Piper ME, Smith SS, Schlam TR, Fiore MC, Jorenby DE, Fraser D, et al: A randomized placebo-controlled clinical trial of 5 smoking cessation pharmacotherapies. Arch Gen Psychiatry 2009, 66:1253-62.

118. Hilleman DE, Mohiuddin SM, Delcore MG: Comparison of fixed-dose transdermal nicotine, tapered-dose transdermal nicotine, and buspirone in smoking cessation. J Clin Pharmacol 1994, 34:222-4.

119. Orleans CT, Resch N, Noll E, Keintz MK, Rimer BK, Brown TV, et al: Use of transdermal nicotine in a state-level prescription plan for the elderly. A first look at 'real-world' patch users. Jama 1994, 271:601-7.

120. Smith TM, Winters FD: Smoking cessation: a clinical study of the transdermal nicotine patch. J Am Osteopath Assoc 1995, 95:655-6, 61-2.

121. Martin PD, Robinson GM: The safety, tolerability and efficacy of transdermal nicotine (Nicotinell TTS) in initially hospitalised patients. N Z Med J 1995, 108:6-8.

122. Fredrickson PA, Hurt RD, Lee GM, Wingender L, Croghan IT, Lauger G, et al: High dose transdermal nicotine therapy for heavy smokers: safety, tolerability and measurement of nicotine and cotinine levels. Psychopharmacology (Berl) 1995, 122:215-22.

123. Jorenby DE, Smith SS, Fiore MC, Hurt RD, Offord KP, Croghan IT, et al: Varying nicotine patch dose and type of smoking cessation counseling. Jama 1995, 274:1347-52

124. Smith TA, House RF Jr, Croghan IT, Gauvin TR, Colligan RC, Offord KP, et al: Nicotine patch therapy in adolescent smokers. Pediatrics 1996, 98:659-67.

125. Hurt RD, Dale LC, Croghan GA, Croghan IT, Gomez-Dahl LC, Offord KP: Nicotine nasal spray for smoking cessation: pattern of use, side effects, relief of withdrawal symptoms, and cotinine levels. Mayo Clin Proc 1998 73:118-25.

126. Gourlay SG, Forbes A, Marriner T, McNeil JJ: Predictors and timing of adverse experiences during trandsdermal nicotine therapy. Drug Saf 1999, 20:545-55.

127. Killen JD, Fortmann SP, Davis L, Strausberg L, Varady A: Do heavy smokers benefit from higher dose nicotine patch therapy? Exp Clin Psychopharmacol 1999, 7:226-33.

128. Hurt RD, Croghan GA, Beede SD, Wolter TD, Croghan IT, Patten CA: Nicotine patch therapy in 101 adolescent smokers: efficacy, withdrawal symptom relief, and carbon monoxide and plasma cotinine levels. Arch Pediatr Adolesc Med 2000, 154:31-7.

129. Shiffman S, Rolf CN, Hellebusch SJ, Gorsline J, Gorodetzky CW, Chiang YK, et al: Real-world efficacy of prescription and over-the-counter nicotine replacement therapy. Addiction 2002, 97:505-16.

130. Croghan GA, Sloan JA, Croghan IT, Novotny P, Hurt RD, DeKrey WL, et al: Comparison of nicotine patch alone versus nicotine nasal spray alone versus a combination for treating smokers: a minimal intervention, randomized multicenter trial in a nonspecialized setting. Nicotine Tob Res 2003, 5:181-7.

131. Hasford J, Fagerstrom KO, Haustein KO: A naturalistic cohort study on effectiveness, safety and usage pattern of an over-the-counter nicotine patch. Cohort study on smoking cessation. Eur J Clin Pharmacol 2003, 59:443-7.

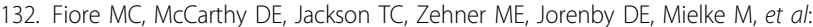
Integrating smoking cessation treatment into primary care: an effectiveness study. Prev Med 2004, 38:412-20.

133. Carpenter MJ, Hughes JR, Solomon LJ, Callas PW: Both smoking reduction with nicotine replacement therapy and motivational advice increase future cessation among smokers unmotivated to quit. J Consult Clin Psychol 2004, 72:371-81.

134. Lerman C, Kaufmann V, Rukstalis M, Patterson F, Perkins K, AudrainMcGovern J, et al: Individualizing nicotine replacement therapy for the treatment of tobacco dependence: a randomized trial. Ann Intern Med 2004, 140:426-33.

135. Hughes JR, Adams EH, Franzon MA, Maguire MK, Guary J: A prospective study of off-label use of, abuse of, and dependence on nicotine inhaler. Tob Control 2005, 14:49-54.

136. Marsh HS, Dresler CM, Choi JH, Targett DA, Gamble ML, Strahs KR: Safety profile of a nicotine lozenge compared with that of nicotine gum in adult smokers with underlying medical conditions: a 12-week, randomized, open-label study. Clin Ther 2005, 27:1571-87.

137. Bolliger $C T$, van Biljon $X$, Axelsson A: A nicotine mouth spray for smoking cessation: a pilot study of preference, safety and efficacy. Respiration 2007, 74:196-201.

138. Stapleton JA, Watson L, Spirling LI, Smith R, Milbrandt A, Ratcliffe M, et al: Varenicline in the routine treatment of tobacco dependence: a pre-post comparison with nicotine replacement therapy and an evaluation in those with mental illness. Addiction 2008, 103:146-54.

139. Gunnell D, Irvine D, Wise L, Davies C, Martin RM: Varenicline and suicidal behaviour: a cohort study based on data from the General Practice Research Database. Bmi 2009, 339:b3805.

140. Ossip DJ, Abrams SM, Mahoney MC, Sall D, Cummings KM: Adverse effects with use of nicotine replacement therapy among quitline clients. Nicotine Tob Res 2009, 11:408-17.

141. Steinberg MB, Greenhaus S, Schmelzer AC, Bover MT, Foulds J, Hoover DR, et al: Triple-combination pharmacotherapy for medically ill smokers: a randomized trial. Ann Intern Med 2009, 150:447-54.

142. Oncken C, Dornelas E, Greene J, Sankey H, Glasmann A, Feinn R, et al: Nicotine gum for pregnant smokers: a randomized controlled trial. Obstet Gynecol 2008, 112:859-67.

143. Matthew TP, Herity NA: Acute myocardial infarction soon after nicotine replacement therapy. QJM 2001, 94:503-4.

144. Dacosta A, Guy JM, Tardy B, Gonthier R, Denis L, Lamaud M, et al: Myocardial infarction and nicotine patch: a contributing or causative factor? Eur Heart J 1993, 14:1709-11.

145. Ottervanger JP, Festen JM, de Vries AG, Stricker BH: Acute myocardial infarction while using the nicotine patch. Chest 1995, 107:1765-6.

146. Ottervanger JP, Stricker BH, Klomps HC: Transdermal nicotine: clarifications, side effects, and funding. Jama 1993, 269:1940, author reply -1 . 
147. Rigotti NA, Eagle KA: Atrial fibrillation while chewing nicotine gum. Jama 1986, 255:1018.

148. Warner JG Jr, Little WC: Myocardial infarction in a patient who smoked while wearing a nicotine patch. Ann Intern Med 1994, 120:695.

149. McRobbie H, Hajek P: Nicotine replacement therapy in patients with cardiovascular disease: guidelines for health professionals. Addiction 2001, 96:1547-51.

150. McRobbie H, Hajek P, Gillison F: The relationship between smoking cessation and mouth ulcers. Nicotine Tob Res 2004, 6:655-9.

151. Hughes JR: Smoking and suicide: a brief overview. Drug Alcohol Depend 2008, 98:169-78.

152. Schroeder SA: A 51-year-old woman with bipolar disorder who wants to quit smoking. Jama 2009, 301:522-31.

153. Kyle SD, Morgan K, Espie CA: Insomnia and health-related quality of life. Sleep Med Rev 2009.

154. Fergusson D, Doucette S, Glass KC, Shapiro S, Healy D, Hebert P, et al: Association between suicide attempts and selective serotonin reuptake inhibitors: systematic review of randomised controlled trials. Bmj 2005, 330:396.

155. Borenstein $M$, Hedges L, Higgins JP, Rothstein H: Introduction to Metaanalysis. Wiley, Chichester 2009, 312.

156. Thomsen T, Tonnesen H, Moller AM: Effect of preoperative smoking cessation interventions on postoperative complications and smoking cessation. Br J Surg 2009, 96:451-61.

157. Poldermans D, Bax JJ, Boersma E, De Hert S, Eeckhout E, Fowkes G, et al: Guidelines for pre-operative cardiac risk assessment and perioperative cardiac management in non-cardiac surgery: the Task Force for Preoperative Cardiac Risk Assessment and Perioperative Cardiac Management in Non-cardiac Surgery of the European Society of Cardiology (ESC) and endorsed by the European Society of Anaesthesiology (ESA). Eur Heart J 2009, 30:2769-812.

doi:10.1186/1617-9625-8-8

Cite this article as: Mills et al:: Adverse events associated with nicotine replacement therapy (NRT) for smoking cessation. A systematic review and meta-analysis of one hundred and twenty studies involving 177,390 individuals. Tobacco Induced Diseases 2010 8:8.

\section{Submit your next manuscript to BioMed Central and take full advantage of:}

- Convenient online submission

- Thorough peer review

- No space constraints or color figure charges

- Immediate publication on acceptance

- Inclusion in PubMed, CAS, Scopus and Google Scholar

- Research which is freely available for redistribution 